\title{
Corrigendum: Impact of functional MRI data preprocessing pipeline on default-mode network detectability in patients with disorders of consciousness
}

\section{Adrian S. Andronache ${ }^{1}$, Cristina Rosazza ${ }^{1,2}$, Davide Sattin ${ }^{3}$, Matilde Leonardi $^{3}{ }^{,}$Ludovico D'Incerti $^{1}$ and Ludovico Minati ${ }^{2 *}$}

${ }^{1}$ Neuroradiology Unit, Fondazione IRCCS Istituto Neurologico "Carlo Besta," Milano, Italy

${ }^{2}$ Scientific Department, Fondazione IRCCS Istituto Neurologico "Carlo Besta," Milano, Italy

${ }^{3}$ Neurology, Public Health, Disability Unit, Scientific Department, Fondazione IRCCS Istituto Neurologico "Carlo Besta," Milan, Italy

${ }^{*}$ Correspondence: Iminati@istituto-besta.it

Edited and reviewed by:

Daniel Marcus, Washington University in St. Louis, USA

Keywords: functional MRI (fMRI), resting-state, functional connectivity, disorders of consciousness, vegetative state, minimally-conscious state, data preprocessing

A corrigendum on

Impact of functional MRI data preprocessing pipeline on default-mode network detectability in patients with disorders of consciousness

by Andronache, A., Rosazza, C., Sattin, D., Leonardi, M., D'Incerti, L., Minati, L., et al. (2013) Front. Neuroinform. 7:16. doi: 10.3389/fninf.2013.00016

The authors of the article by Andronache et al. apologize that the funding acknowledgment "The Start-up Coma Research Centre (CRC) project was also supported by the European Foundation for Biomedical
Research (FERB)" was omitted from the original publication.

\section{REFERENCES}

Andronache, A., Rosazza, C., Sattin, D., Leonardi, M., D’Incerti, L., Minati, L., et al. (2013). Impact of functional MRI data preprocessing pipeline on default-mode network detectability in patients with disorders of consciousness. Front. Neuroinform. 7:16. doi: 10.3389/fninf.2013.00016

Conflict of Interest Statement: The authors declare that the research was conducted in the absence of any commercial or financial relationships that could be construed as a potential conflict of interest.

Received: 14 April 2014; accepted: 24 April 2014; published online: 16 May 2014.
Citation: Andronache AS, Rosazza C, Sattin D, Leonardi M, D'Incerti L and Minati L (2014) Corrigendum: Impact of functional MRI data preprocessing pipeline on default-mode network detectability in patients with disorders of consciousness. Front. Neuroinform. 8:50. doi: 10.3389/fninf.2014.00050

This article was submitted to the journal Frontiers in Neuroinformatics.

Copyright (c) 2014 Andronache, Rosazza, Sattin, Leonardi, D'Incerti and Minati. This is an open-access article distributed under the terms of the Creative Commons Attribution License (CC BY). The use, distribution or reproduction in other forums is permitted, provided the original author(s) or licensor are credited and that the original publication in this journal is cited, in accordance with accepted academic practice. No use, distribution or reproduction is permitted which does not comply with these terms. 